\title{
Processing of Chloride-Containing Productive Solutions after Uranium in-situ Leaching by Ion Exchange Method
}

\author{
Svetlana Titova ${ }^{*}$, Sergey Skripchenko, Alexey Smirnov, and Vladimir Rychkov \\ Institute of Physics and Technology, Ural Federal University, Russian Federation
}

*Corresponding author:

email: AvotitMS@mail.ru

Received: March 31, 2018

Accepted: July 6, 2018

DOI: $10.22146 / \mathrm{ijc} .34460$

\begin{abstract}
The uranium sorption from chloride-containing productive solutions using anion-exchange resins was investigated. The vinyl pyridine anion exchanger (VPAE) had the highest values of the sorption capacity, which for the experiment in the static mode was $13 \mathrm{~kg} \mathrm{U} \mathrm{m}^{-3}$, and for the experiment in the dynamic mode, it was equal to $36 \mathrm{~kg} \mathrm{U} \mathrm{m}^{-3}$. The use of VPAE makes it possible for uranium recovery from productive solutions with an increased content of chloride without sacrificing the productivity of the sorption plant. The process of saturated resins regeneration by various reagents was investigated. The use of ammonium nitrate solution with sulfuric acid ensured maximum value of uranium recovery from the saturated resin phase (76-97\%).
\end{abstract}

Keywords: uranium; ion exchange; chloride ion; regeneration

\section{- INTRODUCTION}

Nuclear power is the only real source of energy today. Wherein, reactors for a long time will remain at its base. A uranium serves as raw material for reactors. Therefore, a steadily growing demand for uranium is expected in the long term. According to the basic scenario for the development of the world nuclear power industry, the reactor demand for uranium will increase from the current 73 to $86-88$ thousand tons per year by 2030 [1-3]. During this period, the supply from secondary sources will decrease by more than three times, and the main growth should be ensured by the primary mining of natural uranium, which has no alternative on this horizon. Uranium recovery should increase from the current 62 to 80 thousand tons by 2030, that is, by almost $30 \%$. Moreover, uranium mining at existing mines will be reduced by $20 \%$, and the planned new mines will only be able to compensate for the outgoing capacity. Since 2024, the demand for uranium will exceed supply and the deficit will be more than 18 thousand tons by 2030, and under the aggressive scenario of development of nuclear energy will reach 48 thousand tons [1-6].

Russia is among the countries where the main increase in nuclear power capacities is observed and nuclear power is actively developing. In the next 10 years in Russia, the capacity of nuclear power plants and energy production is expected to be almost doubled [57]. Therefore, in order to provide Russia's nuclear power with the necessary volume of uranium, projects are being developed for the exploitation of new deposits.

Mineral and raw materials base of uranium of the Russian Federation is quite large, its reserves are more than 700 thousand tons. The main uranium reserves are associated with four areas: Streltsovsky, Vitim, Transural, and Elkonsky [6-8]. Currently, active development of projects for the industrial exploitation of new facilities in the Vitim and Transural districts is being carried out based on the method of in situ leaching (ISL) [6-7,9-11]. However, the rapid development of new deposits is hindered by the increased mineralization of productive solutions. In the course of geological prospecting and experimental work, it was found that an increased content of chloride ions (up to $0.25 \mathrm{M} \mathrm{Cl}^{-}$) is observed in productive solutions (ISL solutions) during the processing of new objects by the method of in situ leaching. The presence of chloride ions suppresses the uranium recovery by anion exchangers [12-14]. The process of uranium sorption by ion exchange resin is the basis of a large amount of technological schemes for reprocessing productive solutions [15-19]. Therefore, in this paper, the processes of uranium sorption from ISL 
solutions with an increased content of chloride ions by using of industrial grade ion exchangers have been studied, and various options for the subsequent regeneration of saturated resins have been considered. The main purpose of the work was to determine the conditions of sorption, which ensure a high efficiency of uranium recovery into the anion exchanger phase with a minimum decrease in sorbent capacity and sorption plant efficiency.

\section{- EXPERIMENTAL SECTION}

\section{Materials}

Tulsion A-233U (Thermax Ltd, India), Lewatit K6367 (Lanxess Deutschland GmbH, Germany), anion exchanger with benzyl pyridine functional groups AMP (Smoly State Company, Ukraine), Purolite A660/4759 (Purolite Ltd, the United Kingdom), vinyl pyridine anion exchanger VPAE (Russia), sodium chloride, ammonium carbonate/bicarbonate mixture (ACBM), ammonium nitrate, sulfuric acid, uranium concentrate were used as materials in this research.

\section{Instrumentation}

Optima 2100 DV (Perkin Elmer, USA) was used to determine the content of uranium in solutions. The automatic shaker IKA KS 3000 i control was applied to mix phases in the study of sorption and regeneration processes in static mode. The automatic LAMBDA OMNICOLL fraction collector, IPC Ismatec peristaltic pump and thermostat Huber Compatible Control CC2 were used for investigation of the sorption and regeneration processes in dynamic mode.

\section{Procedure}

\section{Uranium sorption}

Sorption recovery of uranium was carried out from productive solutions prepared by dissolving of appropriate samples of uranium concentrate and the subsequent addition of sulfuric acid and sodium chloride. The capacity of saturated ion exchanger Purolite A660/4759 was equal 8-14 $\mathrm{kg} \mathrm{U} \mathrm{m}^{-3}$. The capacity value of VPAE was 25-32 $\mathrm{kg} \mathrm{U} \mathrm{m}^{-3}$.

Sorption in static mode. The sorption process was carried out in a cylindrical closed vessel with a volume of
$250 \mathrm{~mL}$ at room temperature and constant shaking. The weight of the resin samples was $50 \mathrm{mg}$. The loading volume of the productive solution containing $30 \mathrm{mg} \mathrm{L}^{-1}$ $\mathrm{U}, 0.05 \mathrm{~mol} \mathrm{~L}^{-1} \mathrm{H}_{2} \mathrm{SO}_{4}$ and $0-6 \mathrm{M} \mathrm{Cl}^{-}$was $100 \mathrm{~mL}$. The contact time of the phases was 24 hours. At the end of the experiment, the anion exchangers were separated by filtration, and the solutions were analyzed for uranium content by the ICP-AES method. Based on the analysis results, the static exchange capacity of anion exchangers for uranium was calculated.

Sorption in dynamic mode. To determine the yield curve of the sorption, $5 \mathrm{~mL}$ of the swollen anion exchanger was loaded into a laboratory vertically located column. Productive solutions containing $30 \mathrm{mg} \mathrm{L}^{-1} \mathrm{U}$, $0.05 \mathrm{~mol} \mathrm{~L}^{-1}$, and $0.25 \mathrm{M} \mathrm{Cl}^{-}$were filtered continuously through a column at a constant rate of $25 \mathrm{~mL} \mathrm{~h}^{-1}$ using a peristaltic pump. The filtrate (the solution leaving the column) was collected in fractions of $50-200 \mathrm{~mL}$ and then was analyzed for uranium content by the ICP-AES method. The sorption process was finished after equalizing of uranium concentrations in the solution at the inlet and outlet of the column.

\section{Saturated resins regeneration}

The choice of elution parameters was made based on an analysis of the industrial experience of the exploitation of sorption technologies for the processing of uranium in-situ leaching solutions. The process of desorption of uranium from saturated anion exchangers was carried out in static and dynamic modes using three different eluents: solutions of sodium chloride (0.5-6 M), solutions of ammonium carbonate/bicarbonate (50-180 $\left.\mathrm{g} \mathrm{L}^{-1}\right)$ and nitrate-sulfate solutions (20-80 $\mathrm{g} \mathrm{L}^{-1}$ $\left.\mathrm{NO}_{3}{ }^{-}+0.1-0.25 \mathrm{~mol} \mathrm{~L}^{-1} \mathrm{H}_{2} \mathrm{SO}_{4}\right)$. The solutions were prepared by dissolving of weighed portions of reagents in distilled water.

Regeneration in static mode. The elution process was carried out in a cylindrical closed vessel of $250 \mathrm{~mL}$ volume at room temperature and constant shaking. The volume of the saturated anion exchanger samples was 1.6-1.8 $\mathrm{mL}$. The ratio of the solid and liquid phases was 1:10. The contact time of the phases was $2 \mathrm{~h}$. At the end of the experiment, the ion exchangers were separated by filtration, and solutions were analyzed for uranium 
content by the ICP-AES method. According to the analysis, the uranium recovery was calculated.

Regeneration in dynamic mode. A sample of saturated anion exchangers in a volume of $5 \mathrm{~mL}$ was loaded into a laboratory vertical column. The feeding of the eluents was carried out continuously by means of a peristaltic pump with a constant rate of $7 \mathrm{~mL} \mathrm{~h}^{-1}$. Fractions of eluent were collected at the outlet of a column throughout the regeneration process and then were analyzed for uranium content by the ICP-AES method. To ensure the maximum recovery of uranium, the elution process with ammonium carbonate/bicarbonate solutions was carried out in two stages at a temperature of $40-50{ }^{\circ} \mathrm{C}$. In the first stage, a solution of ACBM with a concentration of $100 \mathrm{~g} \mathrm{~L}^{-1}$ was used, on the second stage, an ACBM concentration was equal to $140 \mathrm{~g} \mathrm{~L}^{-1}$. The regeneration process was carried out in a column with a jacket. Increased temperature and a gradual growth in the content of ACBM in solution avoids the precipitation of ammonium uranyl tricarbonate in the resin phase.

\section{- RESULTS AND DISCUSSION}

\section{Uranium Sorption}

\section{Sorption in static mode}

According to the results of the studies presented in Table 1, in case of sorption from productive solutions (30 mg L $\mathrm{m}^{-1} \mathrm{U}, 0.05 \mathrm{~mol} \mathrm{~L}^{-1} \mathrm{H}_{2} \mathrm{SO}_{4}$ ) in static mode, the uranium capacity increases in the following order of ion exchangers: Tulsion A-233U - Lewatit K6367 - AMP -
Purolite A660/4759 - VPAE. A decrease in the capacitance characteristics for uranium of all resins was observed during the sorption from productive solutions with an increased content of chloride ions $\left(0.25 \mathrm{M} \mathrm{Cl}^{-}\right)$, due to the competing $\mathrm{Cl}^{-}$-ions sorption process. For the resins, Tulsion A-233U, Lewatit K6367, AMP and Purolite A660/4759, the value of static capacity for uranium decreased by 2.5-4 times. Under these conditions the macroporous ion exchanger VPAE showed the best sorption properties, the capacity value for uranium for this grade of ion exchanger decreased by less than 1.5 times and amounted to $13.2 \mathrm{~kg} \mathrm{U} \mathrm{m}^{-3}$. High capacitance characteristics of VPAE are due to the presence of vinyl pyridine groups in the anion exchanger, which are highly selective for uranyl ions.

Choice of the concentration of chloride ions in productive solutions $(0.25 \mathrm{M})$ for studies was caused by the results of aquifer solutions analysis of a number of uranium deposits currently being developed in Russia. However, during the exploitation of deposits, the accumulation of $\mathrm{Cl}^{-}$in solutions is possible. Therefore, to evaluate the effect of the chloride ion content in the productive solution on the capacitive characteristics of ion exchangers, a series of experiments were performed in a static mode using Purolite A660/4759 and VPAE. Sorption recovery of uranium was carried out from solutions containing $30 \mathrm{mg} \mathrm{L}^{-1} \mathrm{U}, 0.05 \mathrm{~mol} \mathrm{~L}^{-1} \mathrm{H}_{2} \mathrm{SO}_{4}$ and 0-6 $\mathrm{M} \mathrm{Cl}^{-}$. According to the experimental data (Table 2), in the range of $\mathrm{Cl}^{-}$concentrations in the 0-2 $\mathrm{M}$

Table 1. Sorption capacity values in static mode experiment $\left(\mathrm{kg} \mathrm{U} \mathrm{m}^{-3}\right)$

\begin{tabular}{lcc}
\hline \multirow{2}{*}{ Anion Exchanger } & \multicolumn{2}{c}{ The content of $\mathrm{Cl}^{-}$in productive solutions, $\mathrm{M}$} \\
\cline { 2 - 3 } & - & 0.25 \\
\hline Tulsion A-233U & 8.5 & 2.1 \\
Lewatit K6367 & 8.7 & 2.3 \\
AMP & 13.1 & 3.2 \\
Purolite A660/4759 & 17.2 & 6.5 \\
VPAE & 18.6 & 13.2 \\
\hline
\end{tabular}

Table 2. The effect of the chloride ion content in the productive solution on the capacity of anion exchangers $\left(\mathrm{kg} \mathrm{U} \mathrm{m}^{-3}\right)$

\begin{tabular}{llllllll}
\hline \multirow{2}{*}{ Anion Exchanger } & \multicolumn{6}{c}{ The content of $\mathrm{Cl}^{-}$in productive solutions, $\mathrm{M}$} \\
\cline { 2 - 8 } & 0 & 0.25 & 0.5 & 1.0 & 2.0 & 4.0 & 6.0 \\
\hline Purolite A660/4759 & 19.7 & 7.1 & 0.6 & 0.01 & 0.4 & 1.7 & 4.9 \\
VPAE & 20.5 & 13.0 & 0.2 & 0.1 & 0.1 & 0.8 & 4.5 \\
\hline
\end{tabular}




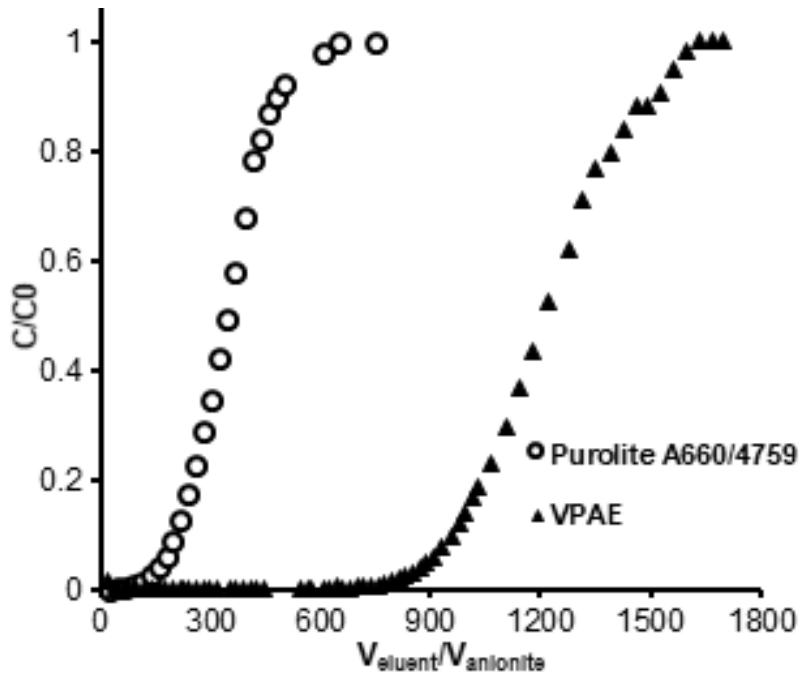

Fig 1. The curves of uranium sorption by anion exchangers Purolite A660/4759 and VPAE

solution, the capacity of the ion exchangers for uranium sharply decreases. This is due to the competitive sorption of $\mathrm{Cl}^{-}$and an increase in the proportion of uranium in the solution bound to the $\mathrm{UO}_{2} \mathrm{Cl}^{+}$complex.

With a chloride ion content of more than 2-3 M, there is a noticeable increase in the sorption of uranium, which is due to a change in the form of its presence in solution. A significant amount of anionic complex ions of uranium $\mathrm{UO}_{2} \mathrm{Cl}_{3}{ }^{-}$appears in this case. In addition, the share of the neutral complex $\mathrm{UO}_{2} \mathrm{Cl}_{2}$ increases, in the presence of which sorption proceeds by the reaction of addition and of the formation of a more highly coordinated complex ion [20]. Complete binding of uranium to neutral and anionic chloride complexes does not occur (even at $6 \mathrm{M} \mathrm{Cl}^{-}$); therefore, when uranium is recovered by anion exchangers from productive solutions with a high content of chloride ions in a dynamic mode, an appreciable part of uranium will remain in the filtrate.

Thus, in the case of accumulation of chloride ions in productive solutions, it is not possible to carry out effective sorption processing using anion exchangers.

\section{Sorption in dynamic mode}

To study the process of sorption of uranium from productive solutions under dynamic conditions, the Purolite A660/4759 and VPAE anion exchangers were selected because these resins showed the best capacitive characteristics for uranium during the sorption experiments in static mode. Sorption recovery of uranium in a dynamic mode was carried out from solutions containing $30 \mathrm{mg} \mathrm{L}^{-1} \mathrm{U}, 0.05 \mathrm{~mol} \mathrm{~L}^{-1} \mathrm{H}_{2} \mathrm{SO}_{4}$ and $0.25 \mathrm{M} \mathrm{Cl}^{-}$. Fig. 1 shows the uranium sorption curves for Purolite A660/4759 and VPAE anion exchangers. According to the data obtained, the use of Purolite A660/4759 for the sorption recovery of uranium from the productive solutions with an increased content of chloride ions is not effective. Saturation of the resin with uranium is achieved in $130 \mathrm{~h}$, while the dynamic capacity value for uranium is no more than $10 \mathrm{~kg} \mathrm{U} \mathrm{m}^{-3}$. The content of uranium in outlet solutions ("tails") for further effective implementation of the in-situ leaching process at the enterprise is regulated at the level of $1 \mathrm{mg} \mathrm{L}^{-1}$. For the Purolite A660/4759, the dynamic capacity is 4$5 \mathrm{~kg} \mathrm{U} \mathrm{m}^{-3}$ at uranium concentration in "tails" of $1 \mathrm{mg} \mathrm{L}^{-1}$. According to the results of the research, the full saturation time of the ion exchanger VPAE is about $330 \mathrm{~h}$ and wherein its capacity is $36 \mathrm{~kg} \mathrm{U} \mathrm{m}^{-3}$. The value of sorption capacity at uranium content in "tails" of $1 \mathrm{mg} \mathrm{L}^{-1}$ is $26 \mathrm{~kg} \mathrm{U} \mathrm{m}^{-3}$.

At present, in Russian uranium industry enterprises, the capacity value of the used anion exchangers at full saturation during the sorption processing of productive solutions (without excess $\mathrm{Cl}^{-}$) is $35-40 \mathrm{~kg} \mathrm{U} \mathrm{m}^{-3}$ [10]. Consequently, the use of VPAE anion exchanger will make it possible to extract uranium from productive solutions with an increased content of chloride ions without reducing the productivity of the sorption plant.

\section{Saturated Resins Regeneration}

\section{Regeneration in static mode}

To determine the reagent scheme for the regeneration of saturated anion exchangers, a series of experiments were carried out. The Purolite A660/4759 and VPAE resins were used in the work. The process of uranium elution from saturated anion exchangers under static conditions was carried out using three different eluents: solutions of sodium chloride (0.5-6 M), solutions of the ammonium carbonate/bicarbonate (50$\left.180 \mathrm{~g} \mathrm{~L}^{-1}\right)$, as well as nitrate-sulfate solutions $\left(20-80 \mathrm{~g} \mathrm{~L}^{-1}\right.$ $\mathrm{NO}_{3}{ }^{-}+0.1-0.25 \mathrm{~mol} \mathrm{~L}^{-1} \mathrm{H}_{2} \mathrm{SO}_{4}$ ) [21-24] 


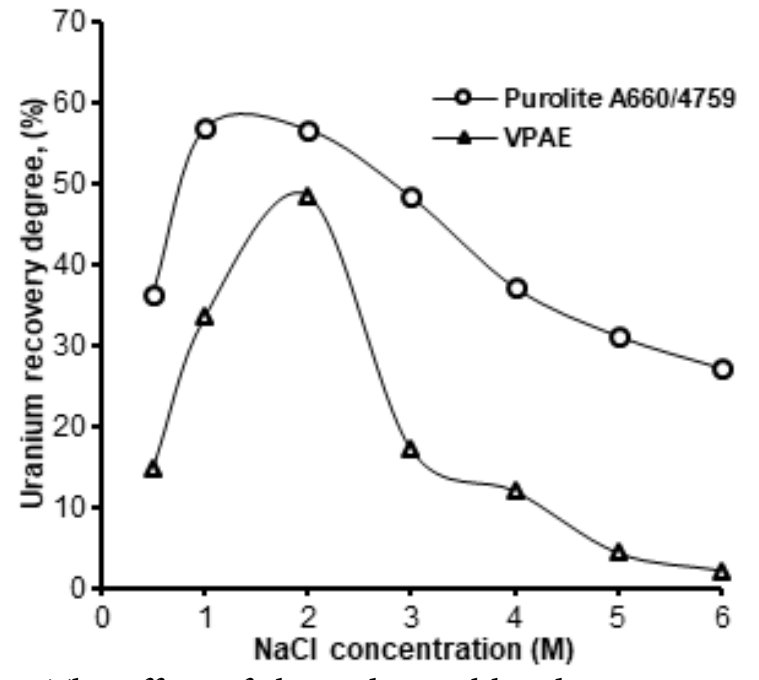

Fig 2. The effect of the sodium chloride content in the eluent solution on the degree of uranium recovery from the saturated ion exchanger

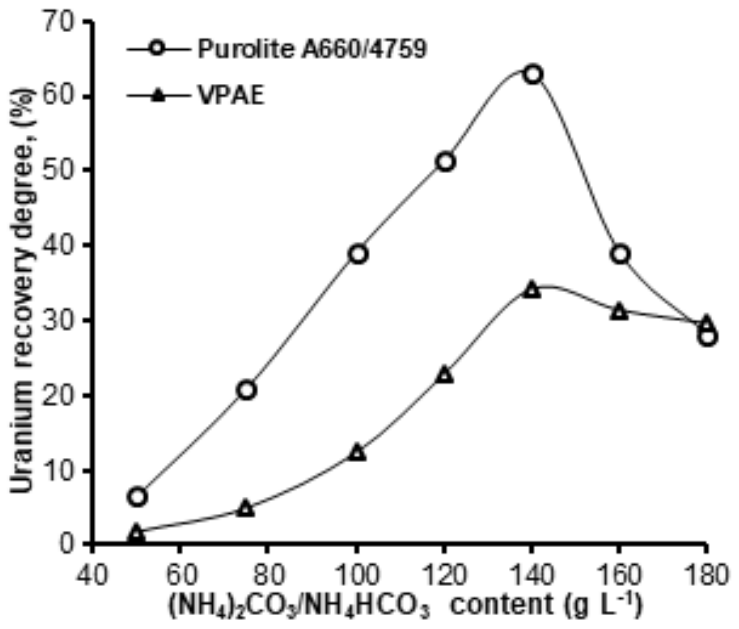

Fig 3. The effect of the of the ammonium carbonate/bicarbonate content in the eluent solution on the degree of uranium recovery from the saturated ion exchanger
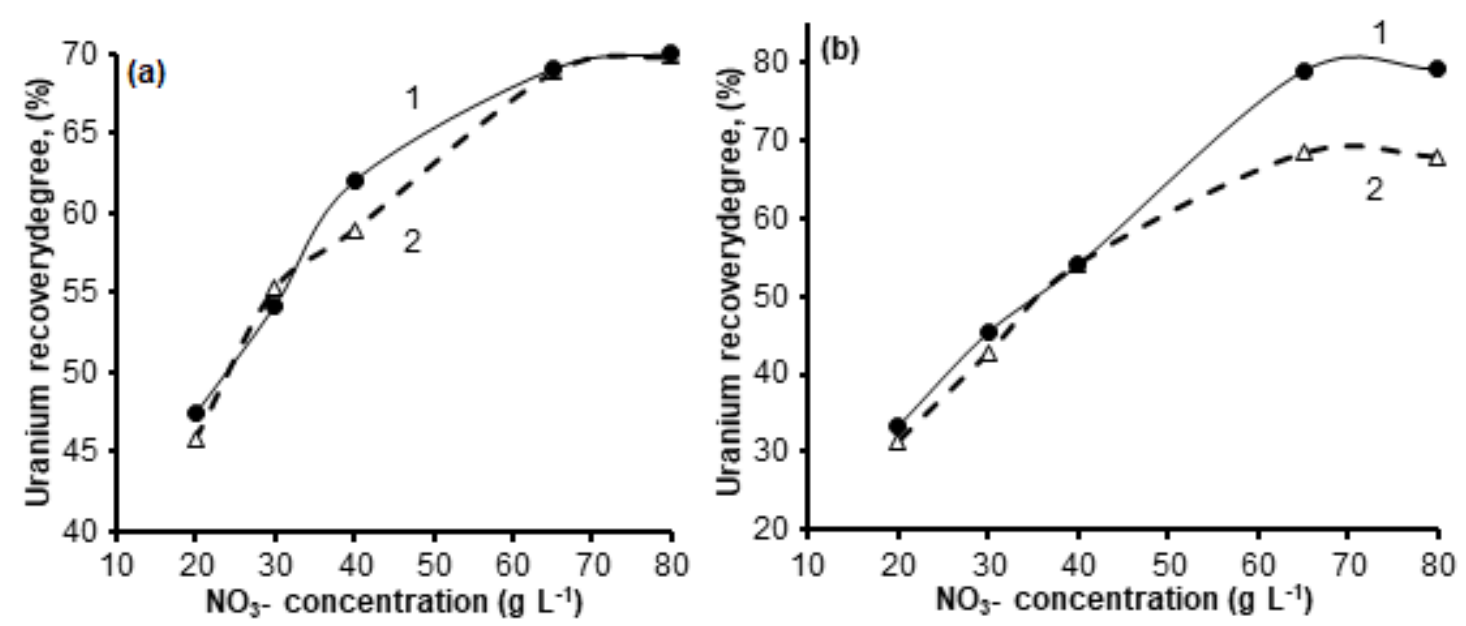

Fig 4. The effect of the eluent solution composition on the uranium recovery from the saturated ion exchange phase Purolite A660/4759 (a) and VPAE (b): 1 - nitrate solution with $0.25 \mathrm{~mol} \mathrm{~L}^{-1} \mathrm{H}_{2} \mathrm{SO}_{4} ; 2$ - nitrate solution with $0.1 \mathrm{~mol} \mathrm{~L}^{-1}$ $\mathrm{H}_{2} \mathrm{SO}_{4}$

According to the research results, when the chloride elution scheme is implemented, the uranium recovery from the saturated anion exchanger phase increases with growth $\mathrm{NaCl}$ concentration in the solution in the range 0.5-2 $\mathrm{M}$ (Fig. 2). With a $\mathrm{NaCl}$ content in the desorption solution of $2 \mathrm{M}$, the uranium recovery degree for Purolite A660/4759 and VPAE anion exchangers is 57 and 48\%, respectively. Further growth of the $\mathrm{NaCl}$ content in the solution adversely affects the degree of uranium recovery. This is due to the formation of a neutral complex of
$\mathrm{UO}_{2} \mathrm{Cl}_{2}$ and an anionic complex of $\mathrm{UO}_{2} \mathrm{Cl}_{3}{ }^{-}$, which are extracted by anion exchangers [19].

An analogous character of the dependence of the uranium recovery degree on the reagent concentration was obtained when using solutions of the ammonium carbonate/bicarbonate. An increase in the uranium recovery from the saturated anion exchanger phase is observed in the concentration range of ACBM 50$160 \mathrm{~g} \mathrm{~L}^{-1}$, a further increase in the content of ACBM leads to a decrease in the efficiency of the process (Fig. 3). During 
Table 3. The effect of the composition of the eluent solution on the uranium recovery rate (\%)

\begin{tabular}{lccc}
\hline \multirow{2}{*}{ Anion Exchanger } & \multicolumn{3}{c}{ The composition of the eluent solution } \\
\cline { 2 - 4 } & $2 \mathrm{M} \mathrm{NaCl}$ & $100-140 \mathrm{~g} \mathrm{~L}^{-1} \mathrm{ACBM}$ & $65 \mathrm{~g} \mathrm{~L}^{-1} \mathrm{NH}_{4} \mathrm{NO}_{3}+0.25 \mathrm{~mol} \mathrm{~L}^{-1} \mathrm{H}_{2} \mathrm{SO}_{4}$ \\
\hline Purolite A660/4759 & 63.4 & 71.2 & 97.1 \\
VPAE & 55.7 & 36.7 & 76.6 \\
\hline
\end{tabular}

desorption, uranium passes into the solution mainly in the form of anionic forms $\left[\mathrm{UO}_{2}\left(\mathrm{CO}_{3}\right)_{2}\right]^{2-}$ and $\left[\mathrm{UO}_{2}\left(\mathrm{CO}_{3}\right)_{3}\right]^{4-}$. As the carbonate ion content and $\mathrm{pH}$ increase, the stability of anionic carbonate complexes of uranium increases, in addition, the equilibrium shifts toward the formation of $\left[\mathrm{UO}_{2}\left(\mathrm{CO}_{3}\right)_{3}\right]^{4-}[21]$. The high strength and high charge of the carbonate complex anion of uranium contribute to its sorption by the anion exchanger, which leads to a decrease in the degree of the metal recovery from the saturated resin phase. The maximum value of the uranium desorption degree is 63 and $34 \%$ for Purolite A660/4759 and VPAE anion exchangers, respectively and it is observed when regenerating with solutions containing $140 \mathrm{~g} \mathrm{~L}^{-1}$ ammonium carbonate/bicarbonate.

According to the results of the research, the use of nitrate-sulfate solutions at the stage of uranium elution is most effective. When the saturated anion exchangers Purolite A660/4759 and VPAE are regenerated, the uranium recovery degree increases with growth nitrate and sulfuric acid content in the solution (Fig. 4). In the case of VPAE anionite, the effect of the concentration of sulfuric acid on the uranium recovery is enhanced at a $\mathrm{NO}_{3}{ }^{-}$concentration in a solution of more than $40 \mathrm{~g} \mathrm{~L}^{-1}$. The maximum recovery for Purolite A660/4759 and VPAE anion exchangers is 70 and $79 \%$, respectively.

\section{Regeneration in dynamic mode}

According to the results of an experiment in the static mode, three eluents were chosen for the dynamic elution process: a sodium chloride solution (2 M), a solution of an ammonium carbonate/bicarbonate (100$\left.140 \mathrm{~g} \mathrm{~L}^{-1}\right)$, and a nitrate-sulfate solution $\left(65 \mathrm{~g} \mathrm{~L}^{-1} \mathrm{NO}_{3}{ }^{-}+\right.$ $0.25 \mathrm{~mol} \mathrm{~L}^{-1} \mathrm{H}_{2} \mathrm{SO}_{4}$ ). The results of the experiments are presented in Table 3.

According to the results of the research, the use of nitrate-sulfate solutions at the elution stage ensures maximum uranium recovery degree from the saturated anion exchanger phase, and its values equal 97.1 and $76.6 \%$ for Purolite A660/4759 and VPAE respectively. When using sodium chloride and ammonium carbonate/bicarbonate solutions for regeneration, uranium recovery degree is lower by more than $20 \%$. Thus, the application of the nitrate-sulfate scheme of uranium recovery in the regeneration stage of saturated anion exchangers is most effective.

\section{- CONCLUSION}

According to the results of the experiment of uranium sorption from productive solutions with a chloride ion content of $0.25 \mathrm{M}$ in static mode, the value of sorption capacity increases in the following order of ion exchangers: Tulsion A-233U - Lewatit K6367 - AMP - Purolite A660/4759 - VPAE. The value of VPAE sorption capacity in static mode is about $13 \mathrm{~kg} \mathrm{U} \mathrm{m}^{-3}$. The total capacity of the VPAE anion exchanger at sorption from productive solutions with a high content of chloride ions $\left(0.25 \mathrm{M} \mathrm{Cl}^{-}\right)$is $36 \mathrm{~kg} \mathrm{U} \mathrm{m}^{-3}$. This allows the use of VPAE resin to recover uranium from productive solutions with increased chloride ion content without reducing the productivity of the sorption plant. The use of nitrate-sulfate solutions at the regeneration stage ensures the maximum recovery of uranium from the saturated anion exchanger phase. When using solutions of sodium chloride and ammonium carbonate/bicarbonate, the uranium recovery degree is much lower. For the VPAE resin, the uranium desorption degree for the nitrate-sulfate reagent scheme is $76.6 \%$. Thus, a technological scheme for the processing of uranium productive solutions with an increased content of chloride ions includes the following main stages: 1 . Sorption of uranium from productive solutions with the use of VPAE anion exchange resin; 2 . Uranium recovery from the saturated VPAE phase using nitrate-sulfate solutions $\left(65 \mathrm{~g} \mathrm{~L}^{-1} \mathrm{NH}_{4} \mathrm{NO}_{3}+0.25 \mathrm{~mol} \mathrm{~L}^{-1}\right.$ $\mathrm{H}_{2} \mathrm{SO}_{4}$ ) as eluent. 
Precipitation of uranium concentrates from the pregnant solutions obtained after resin regeneration is supposed to be carried out using solutions of ammonia and ammonium carbonate/bicarbonate. This method can ensure the production of high purity yellow cake that meets the requirements of ASTM C967-13 [25].

\section{- ACKNOWLEDGMENTS}

The study was financially supported by the Ministry of Education and Science of the Russian Federation within the framework of subsidizing agreement of September 26, 2017 (No. 14.575.21.0137, unique agreement identifier RFMEFI57517X0137) of the Federal Target Program "Research and development in priority directions of the progress of the scientific and technological complex of Russia for the years 2014-2020".

\section{- REFERENCES}

[1] Ux Consulting Company, 2017, Uranium Market Outlook - Q1, UxC, Roswell.

[2] Ux Consulting Company, 2017, Uranium Market Outlook - Q2, UxC, Roswell.

[3] World Nuclear Association, 2017, The Nuclear Fuel Report. Global Scenarios for Demand and Supply Availability 2017-2035, World Nuclear University Press, London.

[4] Boytsov, A.V., 2017, World uranium industry: Status, prospects of development, challenges of time, Actual problems of the uranium industry, Astana, 1421.

[5] Shatalov, V.V., and Tarkhanov, A.V., 2009, Present status of the world and Russian uranium mineralraw material resources, At. Energy, 107 (5), 310-316.

[6] The Nuclear Energy Agency and the International Atomic Energy Agency, 2016, Uranium 2016: Resources, Production and Demand, OECD.

[7] Khlopkov, A., and Chekina, V., 2014, Governing uranium in Russia, DIIS Report, No. 2014:19, Danish Institute for International Studies, Copenhagen.

[8] Mashkovtsev, G.A., 2017, Uranium potential of Russia, Actual problems of the uranium industry, Astana, 22-23.
[9] International Atomic Energy Agency, 2016, In Situ Leach Uranium Mining: An Overview of Operations, IAEA, Vienna, 20.

[10] Rychkov, V.N., Poponin, N.A., Smirnov, A.L., Dementiev, A.A., and Golovko, V.V., 2010, Experience in the production of uranium concentrates at JSC Dalur, Actual problems of the uranium industry, Almaty.

[11] Pastukhov, A.M., Rychkov, V.N., and Skripchenko, S.Y., 2015, Thermodynamic modeling of the in-situ leaching of uranium, J. Radioanal. Nucl. Chem., 303 (3), 2053-2057.

[12] Ogden, M.D., Moon, E.M., Wilson, A., and Pepper, S.E., 2017, Application of chelating weak base resin Dowex M4195 to the recovery of uranium from mixed sulfate/chloride media, Chem. Eng. J., 317, 80-89.

[13] Moon, E.M., Ogden, M.D., Griffith, C.S., Wilson, A., and Mata, J.P., 2017, Impact of chloride on uranium(VI) speciation in acidic sulfate ion exchange systems: Towards seawater-tolerant mineral processing circuits, J. Ind. Eng. Chem., 51, 255-263.

[14] Cai, P., Tan, K., Shi, W., Hu, E., and Huang A., 2010, Experimental study of ion exchange and neutralization on acid in situ leach uranium mining wastewater, Mod. Mining, 11, 21-23.

[15] Balanovsky, N.V., Koshcheeva, A.M., and Cherednichenko, A.G., 2016, Synthesis and properties of strongly basic acrylate polyfunctional anion-exchange resin for uranium extraction, Moscow Univ. Chem. Bull., 71 (5-6), 336-340.

[16] Cheira, M.F., Atia, B.M., and Kouraim, M.N., 2017, Uranium(VI) recovery from acidic leach liquor by Ambersep 920 $\mathrm{U} \mathrm{SO}_{4}$ resin: Kinetic, equilibrium and thermodynamic studies, J. Radiat. Res. Appl. Sci., 10 (4), 307-319.

[17] Rychkov, V.N., Smirnov, A.L., Skripchenko, S.Y., Pastukhov, A.M., and Poponin, N.A., 2017, Precipitation of yellowcake from pregnant regenerate by various reagents, J. Radioanal. Nucl. Chem., 314 (3), 1741-1746. 
[18] Guettaf, H., Becis, A., Ferhat, K., Hanou, K., Bouchiha, D., Yakoubi, K., and Ferrad, F., 2009, Concentration-purification of uranium from an acid leaching solution, Physics Procedia, 2 (3), 765-771.

[19] Kolomiets, D.N., Troshkina, I.D., Sheremet'ev, M.F., and Konopleva, L.V., 2005, Sorption of uranium from sulfuric acid leaching solutions by strongly basic anion exchangers, Russ. J. Appl. Chem., 78 (5), 722-726.

[20] Pakholkov, V.S., Denisova, L.A., Rychkov, V.N., and Kurnosenko, N.A., 1988, Sorption of uranium(VI) ions from hydrochloric acid and ammonium chloride solutions by anion exchangers, Sov. Radiochem., 29 (3), 353-358.

[21] Nekrasova, N.A., Kudryavtseva, S.P., Milyutin, V.V., Chuveleva, E.A., Firsova, L.A., and Gelis, V.M., 2008, Sorption of uranium from carbonate solutions on various ion exchangers, Radiochemistry, 50 (2), 180-182.

[22] Nascimento, M.R.L., Fatibello-Filho, O., and Teixeira, L.A., 2004, Recovery of uranium from acid mine drainage waters by ion exchange, Miner. Process. Extr. Metall. Rev., 25 (2), 129-142.

[23] Panturu, E., Filcenco-Olteanu, A., Radu, A.D., and Zlagnean, M., 2017, The influence of ultrasounds on the process of uranium desorption, E3S Web Conf., 18, 01034.

[24] Peganov, V.A., Molchanova, T.V., Akimova, I.D., and Zharova, E.V., 2015, Technology for obtaining natural-uranium concentrates to ASTM C 967-08 specifications, At. Energy, 117 (6), 415-421.

[25] ASTM International, 2013, ASTM C967-13. Standard specification for uranium ore concentrate, ASTM, West Conshohocken. 